\title{
Adoption and use of digital media in election campaigns: Australia, Canada and New Zealand
}

\author{
PETER CHEN * \\ University of Sydney
}

\begin{abstract}
This article examines the role of digital media in three recent national election campaigns: Australia in 2007 and Canada and New Zealand in 2008 ${ }^{1}$. Examining the process of technology adoption and strategic use by parties and individual candidates, it explores similarities and differences in the use of these evolving campaigning channels. Against the current literature on variables influencing technology adoption, specific attention is given to the use of different communication channels as tools to target specific audiences, the adoption of a wide variety of technologies to ensure broad ('mass') reach, and the co-ordination of messages across different platforms. The analysis aims to identify structural, organisational, technological and cultural determinants of variation in the adoption and deployment of these technologies.
\end{abstract}

\section{Introduction}

The electoral impact of technologies such as the internet has been a focus of research for two decades. Considerable attention has been given to the use of different types of technology (see Davis, Owen, Taras \& Ward, 2008), the way in which candidates and parties represent themselves online (e.g. political marketing and technology association as discussed by Margolis \& Resnick, 2000), and the impact of new channels ${ }^{2}$ on normative democratic values (see the 'equalisation-normalisation' debate discussed by Small, 2008a and others).

While normative approaches have emphasised deterministic explanations for patterns of technology adoption (technology characteristics for the cyber-optimists, and structural and lock-in advantages for the pessimists), this article explores a wider range of variables that impact on the way different types of digital media are adopted and employed in political campaigns. These variables range from 'hard' contextual determinants of political competition (for example, political institutions and electoral regulations), to 'softer' factors associated with inter-jurisdictional learning and the norms of presentation, performativity and publication (for example, the "genre effect" discussed by Foot, et al., 2007).

\footnotetext{
The author would like to thank a number of people who assisted in collection of data that contributed to this article: Australian election 2007, Lucas Walsh (collaborator); Canadian election 2008, Lamia Fahmi (research assistance and translation); New Zealand election 2008, Joe Atkinson, Alexander Abraham, Jennifer Curtin, and Edwin de Ronde of the University of Auckland. Interviewees are acknowledged separately. Thanks also go to the Athabasca University for the Academic Research Fund grant to undertake portions of this research, and reviewers who provided useful input into development of this article.

2 Following Rogers' (1983) broad definition of a channel as a means "by which messages get from one individual to another" channel in this context is used as a meta term that sits above technically-defined methods of communication (sub-media) and socially-defined methods of communication (e.g. communication with an online community, or via a specific online genre, such as a blog).
} 
Proponents of contexualism would argue that the relationship between technology and society is complex and dialectical, with the expectation of greater variability in technology adoption and application between countries. This necessitates comparative analysis to isolate the societal and political contextual variables that make a difference in how digital media are employed during elections. Alternatively, an emphasis on genre effects would suggest that more universal factors related to a particular style of communication and presentation are significant drivers of technology adoption. ${ }^{3}$ Finally, one could argue that elements of the above may be operative at the same time, a complex, if not, contradictory hybrid of technological empowerment, normalisation, contextual and genre effects.

This article contributes to the growing cross-national comparisons on the role of digital media in national elections with the intent of addressing the question of the impact of digital media upon democratic practices. This comparison will focus on recent national elections in three Westminster democracies: Australia, New Zealand and Canada. This comparison will assist in addressing what variables have greater explanatory power in shaping the use and impact of digital technologies in three national electoral web spheres, and the role of digital media in modifying democratic processes. The first question focuses on those factors that drive change, the second on the normative impact of changes identified in political practice.

The article is divided into the four sections: The first is methodological. The second situates the article within the dominant themes of the literature followed by a brief overview of key contextual factors. Particular consideration is given to specifying what is meant by democracy and the theorised relationship between democracy and technology. The third section details research findings in terms of candidates, political parties, and the relationship between centralisation and control, a relationship underscored by the parliamentary system and the residual power of television broadcasting in the complex media ecosystem of each country. Finally, the article concludes with analysis and explanations of the particular use and impact of digital media in recent national elections in these parliamentary democracies.

\section{Methods and approach}

The role of digital media in election campaigns has evolved considerably over the last 20 years (Ward, 2008, pp. 2-4). From a purely support role (electoral database, direct mail printing, and graphical design as discussed in Chen, 2005), information and communications technologies (ICTs) have increasingly found a place as direct channels of communication from and to political parties and candidates. Over time this use has developed from simple "emulations" of other forms of media such as the use of candidate websites as static online "brochures" or electronic billboards (Gibson \& Ward, 2002) to increasingly sophisticated campaign tools that are used for mass and select advertising, recruitment and fundraising, and the facilitation of political dialogue. Most recently digital media has become more central to the campaign process with campaigns employing a wider range of digital channels, increased professionalisation, and reintegration of online channels into the core marketing strategies.

The range of channels employed and the tendency for rapid change in political practice between electoral cycles necessitates the use of a variety of research methods to capture comparative data and ensure key changes in practice are not overlooked (Chen \& Walsh,

3 Genre effects refers to situations whereby “... sites produced by the same type of actor and/or sharing a similar purpose often reflect certain regularities of form and function that become associated with the genre of the site by both producers and visitors alike" (Foot, et al., 2008, p. 44). 
2009). For the three elections considered in this article, their temporal closeness assists in comparison (less than one year separates the three election dates) ${ }^{4}$, as the development of new channels (for example, social networking services (SNS)) can make comparisons with older data sets difficult.

In this comparative analysis three research methods were employed:

- Content analysis ${ }^{5}$ of individual candidates' use of a variety of digital media, identifying and quantifying the use and functionality of websites (campaign sites, party "mini-sites"6, third party content hosting ${ }^{7}$ ), accessibility of candidates using electronic mail (e-mail), and the use of, and number of social ties associated with, $\mathrm{SNS}^{8}$ and hybrid systems with SNS characteristics ${ }^{9}$. See Table 1 for sample size;

- A survey of candidates examining computer literacy, use of different communications channels, candidate perceptions of the value of different communications channels, use of information and communications technologies in administrative and support functions in the campaign, and assistance provided by the candidates' political party for different campaigning techniques/channels;

- Semi-structured interviews with party officials from parties of government, and key minor parties (based on electoral results from recent elections).

\section{Sample}

A sample of electorates/electoral districts was selected purposively and content analysis was undertaken of the sites of all candidates in selected districts.

The Australian and Canadian surveys were distributed only to those candidates whose sites were selected for content analysis. The New Zealand election survey was distributed with the New Zealand Candidate Survey undertaken by the University of Auckland to all candidates standing in the election. (See Table 1 for sample numbers.)

4 The Australian election was held on 24 November 2007, the Canadian election on 14 October 2008, and the New Zealand election on 8 November 2008.

5 An example of the coding frame used for this method can be found Chen (2008).

6 Some form of entry on the campaign website of the party. The extent of these varies greatly, from one line entries, to detailed biographies that allowed the candidate to provide additional material (such as online video or a campaign blog). The advantages of these latter type of mini-site are their low cost of deployment (essentially no marginal cost where a party uses an appropriately modern content management system), ease of control by the party to ensure appropriate branding, and the ability of mini-sites to be more easily located via search engines (party sites, as larger websites, are likely to be indexed by search engines more quickly and reviewed more often than sites that are new or have little traffic; Fishkin \& Pollard, 2007).

7 Including standalone blogs.

8 SNS are defined here as technologies that “... that allow individuals to (1) construct a public or semi-public profile within a bounded system, (2) articulate a list of other users with whom they share a connection, and (3) view and traverse their list of connections and those made by others within the system". (Boyd \& Ellison, 2007). Based on available knowledge the local market share of SNS, different services were examined for each election: Australia 2007 (Bebo, Facebook, Flickr, Friendster, LinkedIn, MySpace, Orkut, YouTube); Canada 2008 (Bebo, Facebook, Flickr, Friendster, Hi5, LinkedIn, MySpace, Twitter, YouTube), and; New Zealand 2008 (Bebo, Facebook, Flickr, Friendster, Hi5, LinkedIn, MySpace, OldFriends, Orkut, YouTube). Candidates were identified using the search function included in each service.

9 For example, services like YouTube and Flickr, which are predominantly content hosting systems, but provide social networking tools. The backwards integration of social networking elements to existing online services is likely to be a feature of web development over the coming years (for example, integration of social networking tools into online e-mail (and instant messaging-e-mail hybrids, such as Google Wave) and the development of meta-social networking systems (e.g. Ning). For a similar study of Australian incumbents in the 2007 election, see Australian Centre for Public Communication (2008). 


\begin{tabular}{|l|c|c|c|}
\cline { 2 - 4 } \multicolumn{1}{c|}{} & Australia 2007 & New Zealand 2008 & Canada 2008 \\
\hline Content analysis & 217 & 92 & 217 \\
\hline Candidate survey & 54 & 152 & 38 \\
\hline Semi-structured interviews & 4 & 4 & 4 \\
\hline
\end{tabular}

Table 1: Data collection methods, $n$

\section{Literature: technology, democracy and choice}

The two dominant claims on the impact of digital technologies on democracy implicitly accept the notion of determinism: technological viewing innovation as the most important variable shaping our societal, political and cultural systems, and social in which societal and political factors shape the impact of technology (Anstead \& Chadwick, 2008).

Initial perspectives on the democratic impact of ICTs focused positively on the association between networked computing and reduced barriers to the production and exchange of information (Jenkins \& Thorburn, 2004). Barney, a critic of the inevitability thesis, saw this hope as an article of "faith augmented by an anticipation that the democracy networks will be contagious and impossible to quarantine" (2000, p. 19). This was part of the broader emancipatory discourse surrounding digital media (Malina, 1999).

This initial enthusiasm has been tempered by more thoughtful analyses of the democratic uses of technologies. Barber argues that "there is no simple or general answer to the question 'Is the technology democratising?' until we have made clear what sort of democracy we intend" (1999, p. 585). Barber's preference is for "strong democracy ... understood as deliberative and participatory activity on the part of responsible citizens" (1999, p. 585). The prospects for strong democracy would seemingly be enhanced with the advent of "Web 2.0": "architecture of participation" (O'Reilly, 2005). The development of Web 2.0 focuses attention on bottom-up participatory democracy seen through technologies and practices associated with blogging, citizen journalism, and social networking. Encouraging the development of "produsers" (users who are also producers, as discussed by Bruns, 2008), these enabling technologies facilitate participation, dialogue, and engagement of citizens.

Barber considered representative democracy as "thin" where citizens are encouraged to have more passive roles in the political process $(1999,1998)$. In the thin tradition ICTs act as dispensers of information, rather than deliberative spaces for political action. Here Barber argues that one should not expect much from the advocates of representative democracy who "are properly suspicious of the new technologies and their penchant for immediacy, directness, lateral communication, and undeliberativeness" (1999, p. 585).

This tendency will be reinforced by existing distributions of power. Stranglove argues that "It is generally assumed that online activity and content are becoming a mirror of the corporate mode of cultural production." (2005, p. 20) On the political plane, Resnick argues "if we ask which political parties and candidates are likely to provide sophisticated web sites, the answer is clear: those who command the resources to hire the talent to produce them" $(1999$, p. 63). In brief, the parties with more resources both in terms of money and people are more likely to dominate minor parties at election time. 
These normalisation arguments are counter-indicated by an equalisation thesis which argues that new communications media will enhance political competitiveness. According to Ward, Gibson and Nixon, the equalisation thesis "is based on the ability of small or fringe parties to exploit the relatively low costs of the medium, the lack of editorial control and supposedly non-hierarchical nature of the internet." An advantage that tends to be sustained by rapid developments in technology and the ability of small, less hierarchically structured organisations to take advantage of an environment subject to constant change. The implications may be profound, as "with relatively few skills and resources a minor party can have just as sophisticated a site as a governing party" (2003, p. 22). In this view, ICTs could reinvigorate representative democracy, addressing the "malaise" of weakening legitimacy, falling party membership and voter turnout (where relevant, see below), "voter apathy" and disengagement from formal political processes.

In part to escape the somewhat narrow deterministic confines of the normalisation versus equalisation debate scholars have begun to emphasise a number of interdependencies: between different types of media, and between society and technology (Ward, Gibson \& Nixon, 2003, p. 23). Ward and Gibson go on to "reject ... 'one size fits all' explanations and argue that social and political shaping are crucial to understanding the development of an organisation's approach to new technologies" (2009, p. 35). Similarly, Anstead and Chadwick maintain that "the relationship between technology and political institutions is best perceived as dialectical. Technologies can reshape institutions, but institutions will mediate eventual outcomes" (2009, p. 58).

According to these perspectives one would expect variances in the impact of the internet on election campaigning in different representative democracies. While scholars tend to have their own lists of factors which shape the use of ICTs by political parties during elections three factors in particular are identified in this article: 1) political-systemic; 2) organisational and financial; and 3) media environment. While distinct factors they are not mutually exclusive. The political system, for example, can regulate campaign spending which in turn has an impact on financial resources and how they are used. Each factor is outlined briefly below.

\section{Systemic factors}

The "nested" impact of systematic factors on the way in which political behaviour is undertaken is recognised by authors such as Hofferbert (1974). Through his "funnel of causality", Hofferbert identified historical and geographic factors shaping patterns of development and settlement, socio-economic conditions such as culture and the distribution of resources, mass political behaviour, and the structure of government institutions as cascading causal factors in understanding political and policy outputs.

The social, economic, and political system of a nation can have a significant impact on the use of ICTs. While these impacts shape the distribution of resources, key constitutional factors determine the "rules of the game" or logic behind different political strategies and tactics (Rhodes, 1992, p. 87). A good example of this would be the degree of pluralism produced by a political system and its impact on the use of ICTs in elections. The prime example of this relationship can be seen in the United States where Gibson and Ward state:

Presidential, candidate-centered federal systems are more likely to be responsive to interactive online technologies than highly centralised polities because multilevel government with large numbers of independent actors is likely to result in greater experimentation and innovation in terms of campaigning (Ward \& Gibson, 2009, p. 35). 
On the other hand, a parliamentary, unitary system such as those descended from the United Kingdom is said to foster greater party cohesion and discipline which, in turn, facilitate coordination, integration and control from national headquarters. The result is that the technological affordances of the internet "for creating loose horizontal networks have fewer affinities with this set of arrangements" (Anstead \& Chadwick, 2009, p. 63).

In addition to these "hard" structural factors we must recognise the impact of political culture. The importance of these influences is of particular value to a comparative study of like nations where initial starting conditions (cultural transfer and retransfer, and the adoption of political institutional arrangements from the "home country") are moulded by evolving "values, beliefs, and attitudes within which a political system operates" (Axford, et al., 1997, p. 409). This iterative process means that the symbolic environment of political practice itself moulded by political institutions, history, and the larger culture (Jankowski, 2007) influences the selection, use, and symbolic meaning of technology employed for political purposes.

\section{Organisational factors}

While a host of organisational factors are claimed to have an impact on the adoption and use of ICTs of particular salience are organisational resources and culture. Organisational resources speak principally to capacity: the presence of financial resources, skills, structural capacity, and technical infrastructure. While the equalisation thesis asserts that minor parties can project a sophisticated web presence with the fewer resources, the counterargument is that resources still matter in shaping internet use. According to Ward, "increasingly ... financial and human resources [are] becoming important, as with other types of campaigning" (2008, p. 5). Moreover, the addition of Web 2.0 programming techniques means that websites are becoming more sophisticated, content rich, and time consuming to monitor and maintain - possibly necessitating the need for greater resources to employ effectively (Ward \& Gibson, 2009).

The financial resources available to a candidate or party are themselves subject to a number of influences including political culture (the general expectation, or lack thereof, of political donations) and relevant regulations that limit levels of fundraising, and channel funds that are raised into specific organisations or parts of organisations. Where there are legal restrictions on spending by candidates and/or parties there may be effects on the adoption and use of ICTs in election campaigns. For example, in both the UK and Canada candidates are more restricted than parties by campaign spending limits (Anstead \& Chadwick, 2009; Davis, et al., 2008). According to Davis, et al. "the result is a funnelling of resources to party organisation rather than campaign organisations, and the strengthening of party internet activities rather than candidate online communication" (2008, p. 264). In turn, this result may well heighten and centralise the role of national party headquarters in determining the use of digital media.

Organisational culture, itself a subset of the wider political culture, is also emphasised as a variable shaping the use of ICTs by political parties. (Ward, 2008; Ward \& Gibson, 2008) For example, parties on the left such as the Green Party are often viewed as having a stronger, participatory, grass-roots organisational culture said to have a better fit with the interactive capacities of the internet. On the other hand parties with older consistencies may favour more established communications channels. 


\section{Media effects}

Finally, a range of factors have been identified that shape the way in which digital media are adopted and deployed. While the equalisation thesis (Small, 2008a) draws upon one element of this (characteristics of networked media and their associated low barriers to entry), two additional factors are highlighted here. First, the emerging notion of different media channels as interconnected or existing within a dynamic "media ecosystem". Second, the hypothesis that global stylistic isomorphism is a greater determinant of technology use than domestic variables.

Until recently there has been a tendency to study digital ('new') media separately from 'old' media, reflecting the analytical tradition in the study of communications. As the novelty of digital media has declined, this has lead to recognition of the entrenched role of conventional media in campaign strategies, particularly at the central party level. In addition, scholars of political communication are increasingly cognizant of the interdependent nature of different communications channels. How each media is used depends very much on the characteristics of the medium such as timeliness, influences on the character of message, and likely audience (Ward, 2008), but selection decisions are often made with awareness of the impact of one channel on another - such as 'gatekeeper' effects and through cascading agenda setting (Flew \& Watson, 2008). A good example of this is the use of online media to "win free media" (Yudkin, 2003), such as the production and distribution of video online with the objective of having the content reproduced in news media coverage.

The growing interdependence of 'old' and 'new' media has become a widely accepted feature of contemporary media and election campaigns. The rise of bloggers and alternative journalism, for example, has created a complex interdependence between new media and old media, one that Hiler (2002) calls "mutually parasitic". The use of the biological metaphor has promoted the notion of a media ecology or a media ecosystem with interacting subsystems of old and new media - e.g. television broadcasting, radio, print and internet, the latter with its wide assortment of social networking tools which facilitate increasing amounts of user-generated content (Naughton, 2006; Deuze, 2005). The resulting changing relationships between audience and different media in terms of interactivity, audience sizes, and so on, produce a complex and shifting set of relationships which varies country by country. This produces different effects in terms of centralisation and decentralisation depending on the factors discussed previously in this section.

Finally, recent work by Kluver, et al. (2007) suggests an alternative approach. They argue for the existence of a universal "genre effect" independent of the particularities of geographical and political differences. Their research indicates that political web production tends to be isomorphic in nature as a result of pressures on producers of websites to emulate what other political websites look like, not only meeting the expectations or norms of other producers but also site visitors. In essence, claim Foot, et al. that "the production of a national electoral web sphere happens in a global context: the production practices of one type of actors in a national electoral web sphere are more likely to be like those of the same type of actors in other electoral spheres than like those of other types of actors within the same national electoral web sphere" $(2007$, pp. 258, 259). Thus, the websites of political parties in India are more likely to be similar to those produced by parties in another country than they would be to social movements in these countries. So important is the genre effect that as a result of the comparative analysis of data in over twenty countries the authors conclude "the type of political actor was more potent" than other "variables explaining web production practices" (2007, p. 258). 


\section{Analysis: explaining similarities and differences in three national elections}

This section examines the variables discussed against data collected from the Australian, New Zealand and Canadian national elections. Due to the comparative nature of this analysis, the article includes only a subset of the data collected for each election. For more detailed analysis of the role of digital media and Australian election, see Chen (2008) and Chen and Walsh (2009), for further details in relation to the New Zealand election see Chen (2009), and for more information on the Canadian election see Smith and Chen (2009a, 2009b).

\section{Systemic factors}

\section{i. Underlying technology adoption}

The availability of different media is commonly presented as a driver of the adoption of new channels of communication by political actors making rational resource allocation decisions. Thus, the success of political candidates strongly associated with innovative or extensive use of digital media (e.g. South Korea's Roh Moo-hyun or Barack Obama) is often closely linked with high rates of technology adoption and innovation in those countries. While different communications channels will have benefits in accessing select audiences (see below), it is anticipated that political candidates are generally more likely to employ those channels that have greater potential audiences.

The explanatory value of this position can be examined by comparing known technology adoption rates for the population of each nation (Table 2) to survey data collected regarding candidate preferences ${ }^{10}$ for relevant communications channels (Table 3). This allows comparison between different digital media (internet and mobile cellular ${ }^{11}$ ), between general rates of internet use and the emerging adoption of faster and 'always on' broadband services commonly associated with higher intensity use, and identification of the substitution of new technologies in place of older and established media.

\begin{tabular}{|l|r|r|r|}
\cline { 2 - 4 } \multicolumn{1}{c|}{} & $\begin{array}{r}\text { Broadband } \\
\text { subscribers per 100 } \\
\text { inhabitants }\end{array}$ & $\begin{array}{r}\text { Internet users per 100 } \\
\text { inhabitants }\end{array}$ & $\begin{array}{r}\text { Mobile cellular } \\
\text { subscribers per 100 } \\
\text { inhabitants }\end{array}$ \\
\hline Australia 2007 & 23.29 & 53.99 & 102.49 \\
\hline New Zealand 2008 & 21.71 & 70 & 109.61 \\
\hline Canada 2008 & 29.04 & 73 & 64.68 \\
\hline
\end{tabular}

Table 2: Comparative adoption of digital media among the population. Source: International Telecommunication Union ICT Statistics Database (http://www.itu.int/ITU-

D/ICTEYE/Indicators/Indicators.aspx)

A comparison of these tables shows that there a moderate to strong positive correlation between candidates' value perceptions of high bandwidth-related internet media (online video and broadband adoption, 0.691) and the average value of all web channels and general rates of internet use (0.788) across the three countries. This correlation does not hold, however, with mobile cellular adoption and preferences for short messaging service (-0.567). What this

10 In examining this variable it would appear to be more useful to examine preferences rather than adoption rates, as this would, to some extent, exclude organisational factors (e.g. resources).

11 Cellular, non-internet.

12 Australia and New Zealand have more mobile telephones than people, which reflects the tendency for a proportion of the population (exact amount unknown) to have more than one telephone (Kidman, 2008). 
tells us is that the relationship between underlying social practices (technology adoption by the community) does not directly flow on to political utilisation. This has implications for the mix of explanatory variables used to examine technology adoption, but also for the developmentalist perspective - that is, the argument that the provision of basic infrastructure (connectivity) conveys automatic benefits in terms of democratic or participatory outcomes.

\begin{tabular}{|l|r|r|r|r|}
\cline { 2 - 5 } \multicolumn{1}{c|}{} & $N$ & $\begin{array}{r}\text { Average value of } \\
\text { online video }\end{array}$ & $\begin{array}{r}\text { Average value of } \\
\text { Average value for } \\
\text { internet channels }\end{array}$ & $\begin{array}{r}13 \\
\text { short messaging } \\
\text { service (SMS / } \\
\text { texting) }\end{array}$ \\
\hline Australia 2007 & 54 & 2.57 & 2.69 & 1.94 \\
\hline $\begin{array}{l}\text { New Zealand } \\
\mathbf{2 0 0 8}\end{array}$ & 152 & 2.74 & 2.81 & 2.75 \\
\hline Canada 2008 & 38 & 2.87 & 3.18 & 3.00 \\
\hline
\end{tabular}

Table 3: Self-reported value perceptions of different campaigning channels (four point likert scale). ${ }^{14}$

\section{ii. The 'tyranny of distance'}

The technology adoption rates provided in Table 2 undermine the argument that large developed nations tend - all things being equal - to be rapid adopters of communications technologies as a means of overcoming problems associated with distance (Nieuwenhuysen, Lloyd, \& Mead, 2001, p. 4).

In a similar manner, the available data also undermines the notion of digital media being adopted as a means to compensate for the large distances associated with some types of political campaigning. In centralised party campaigns the vast size of the Australian and Canadian landscapes do not appear to have encouraged a substitution for electronic media in lieu of the established traditional campaigning techniques associated with the campaign "road trip". Indeed, political culture mitigates against this "rational" substitution. As Small (2008b, p. 124) observes: "Leaders are expected to display a kind of campaign machismo by travelling continuously across huge distances...", an expression of political culture that is reinforced by the use of these trips as fodder for local new services and stories. What is interesting is that the increasing consolidation among conventional media has not undermined the political necessity for these trips. Indeed, it is possible to argue that the value of these types of trips has increased specifically because of the decline of local media. Media consolidation increases the value (to commercial media) of having journalists embedded with the travelling leader and ensuring their ignorance of local conditions they are required to produce content on in very short timeframes. ${ }^{15}$

This finding also holds when considering the adoption of digital media by individual candidates, but for different reasons. In none of the countries studied do we see a positive correlation in the use of digital media and electorate sizes. Where large multi-member electorates are involved - eg. the Australian Senate (Chen, 2005) and the New Zealand party 'list' system - there is no bias by Senate or list-only candidates towards the use of digital media. This choice could be expected as a low-cost and potentially effective means of

13 Includes survey responses regarding candidate preferences for: campaign website, e-mail, online video, SNS, and podcasting.

14 1=No value, $2=$ Limited value, $3=$ Some value, $4=$ High value.

15 In Australia this ignorance is enhanced through strict control over access by journalists and not releasing destination information to them. 
reaching these larger constituencies given the cost of mass state-wide or national advertising (electronic or paper). The subordinate nature of individual candidates to the overarching party communications strategy ${ }^{16}$ discourages individual campaigning by these candidates. ${ }^{17}$ The exception to this being individuals in leadership positions (Australia) and the use of high profile list candidates to target specific ethnic communities (such as Chinese speakers on the list ticket in New Zealand).

\section{iii. Candidate centrism ${ }^{18}$}

If the developmentalist perspective has limitations explaining the pattern of technology adoption it is useful to review evidence related the link between political structures and technology choices. Taking Gibson and Ward's (2009) view about the structural impacts of constitutional design on "candidate centrism" we would expect, all other factors equal, to see lower levels of use of digital media by candidates in more centralised political systems. Looking at the three case examples there is a reasonable variation of this measure due to local political-structural conditions, with New Zealand (geographically small, non-federal, unicameral, having a party-centric list-ticket system) ${ }^{19}$ theoretically the nation with the most centralising tendencies, and Canada (federal with strong provinces and bilingualism, geographically dispersed with the most time zones) having the least centralising tendency. Australia (federal with strong central government, concentrated east-cost population, fewer time zones), represents a good midpoint.

Looking at the technology choices of candidates in these counties, therefore, Table 4 would appear to support this basic hypothesis to some degree. While there are minor variations in the use of party-supplied digital channels, for example, party "mini-sites" and e-mail. The rate of adoption of candidate websites (generally considered the most significant aspect of an online campaign due to costs to develop and maintain these channels) follows the hypothesis outlined above. That is, adoption is correlated (from highest to lowest) along the degree of centralisation tendency.

\section{iv. The logic of political competition}

Another structural determinant is the way in which the electoral system affects the logic of political competition. Among the three case examples only Australia possesses compulsory electoral registration (which translates to a high rate of participation). The implications of this for Australia has been an emphasis on the conversion of "swinging" voters - people who have are seen has having a lower party affiliation and are therefore able to be influenced through the use of media (Young, 2002). In Canada and New Zealand, a greater emphasis has been on ensuring voter turnout which tends to be associated with voters who have higher levels of party or issue arousal.

16 This is explicitly recognised in New Zealand through the party list system and in Australia through "the above the line" Senate voting. It is increasingly entrenched through a range of other elements of the electoral systems of Australia and Canada (Canadian fund raising limits, for example, encourages money to be directed to the party over individuals).

17 As illustrated in Figure 4 at end of this paper, this is considerable performance gap in the New Zealand context when compared with both general and Māori electorates. It is important also to recognise that because of their smaller number Māori electorates are considerably physically larger and less densely populated than general electorates in New Zealand.

18 Clearly a misnomer in the Westminster context, which, as we will see, is best described in terms of partyoriented centralisation.

19 However, a countervailing factor is the tendency for split ticket voting in New Zealand which can be argued enhances the independence of candidates who run for general electorates (Johnston \& Pattieb, 2002). This does not appear supported by this data (next paragraph). 


\begin{tabular}{|c|c|c|c|c|c|c|}
\hline & Party(ies) ${ }^{20}$ & $n^{21}$ & Website & Minisite $^{22}$ & E-mail & SNS \\
\hline \multirow{4}{*}{ Australia 2007} & Incumbent $^{23}$ & 33 & 60.61 & 96.97 & 93.94 & 39.39 \\
\hline & Opposition $^{24}$ & 33 & 48.48 & 100.00 & 100.00 & 39.39 \\
\hline & Minor $^{25}$ & 32 & 9.38 & 93.75 & 93.75 & 46.88 \\
\hline & All & 217 (197) & 20.74 & 71.57 & 78.34 & 28.57 \\
\hline \multirow{4}{*}{$\begin{array}{l}\text { New Zealand } \\
2008\end{array}$} & Incumbent $^{26}$ & 13 & 7.69 & 100.00 & 61.54 & 61.54 \\
\hline & Opposition $^{27}$ & 8 & 37.50 & 100.00 & 100.00 & 50.00 \\
\hline & Minor $^{28}$ & 8 & 12.50 & 100.00 & 100.00 & 75.00 \\
\hline & All & $92(86)$ & 13.04 & 81.40 & 58.70 & 51.09 \\
\hline \multirow{4}{*}{ Canada 2008} & Incumbent $^{29}$ & 44 & 95.45 & 100.00 & 95.45 & 63.64 \\
\hline & Opposition $^{30}$ & 44 & 75.00 & 100.00 & 88.64 & 75.00 \\
\hline & Minor $^{31}$ & 44 & 54.55 & 100.00 & 95.45 & 63.64 \\
\hline & All & 217 (210) & 36.94 & 98.10 & 89.40 & 62.67 \\
\hline
\end{tabular}

Table 4: Candidates' use of digital media channels.

The extent to which this difference has affected the use of digital media in these three countries is present, but its effects small. While recognising the potential of direct communication as a 'get out the vote' tool, these systems have either not been developed, or has been used in only a small scale. For example, the National Party of New Zealand has not yet employed these methods but is considering e-mail for this purpose in future (White, personal communication, 2009), while small scale experimentation has been conducted in Canada such as SMS messaging by the Liberal Party in British-Columbia Canada (Miron, personal communication, 2008). In this regard, the Australian context is less clear. Swing voters who engage in strategic decision-making tend to favour the use of 'pull' media where the user is proactive in seeking and selecting relevant content. On the other hand, disengaged voters lead to an emphasis on 'push' media (e.g. mass advertising) as users tend to be more passive receivers of information. In the latter case, considerably more research needs to be done to identify if there is a significant difference at the level of party campaigns, as the different resource base of the three nations makes comparisons problematic.

An additional area of interest is the impact of political competition characteristics on the way in which technology is used politically within the party context. A good example of this is the way in which the list system ${ }^{32}$ in New Zealand creates competition for a second round of selection whereby candidates who may be selected for seats that they are unlikely to win may

20 Selection of "minor" party based on electoral success at the previous election.

21 Bracketed figure sans independent candidates.

22 Excludes independents.

23 Liberal-National coalition.

24 Australian Labor Party.

25 Australian Greens.

26 New Zealand Labour Party.

27 New Zealand Nationals.

28 Green Party of Aotearoa New Zealand.

29 Conservative Party of Canada.

30 Liberal Party of Canada.

31 New Democratic Party.

32 New Zealand is the only unicameral parliament included in this study, but is distinct in that the mixed member proportional system includes two tiers of voting: one vote for the local candidate and one for the party list. 
enter Parliament on the list ticket. For some, this encourages increased campaign activity with the objective of raising the candidates profile within the party, with the expectation that this may increase their ranking on the list ticket (Powell, personal communication, 2008).

\section{Organisational factors}

\section{i. Political parties and money}

The extent, capacity and willingness of political parties to develop and employ digital media is influenced by their financial resources. In the three cases major political parties have begun allocating a small, but increasing proportion of their overall campaign budget to digital media. While the availability of free or low cost systems of online content distribution ${ }^{33}$ has served to ensure that all but the most obscure political parties have a "credible" web presence (White, personal communication, 2009), different levels of resources affect how parties are able to develop a consistently high quality digital presence across a range of channels, and integrate these channels together. Given the population differences between the three countries studied, Table 5 demonstrates the impact of resources on the capacity of parties to create more expensive "rich media". Similarly, the absence of money can reduce the visibility of a party considerably. For example, the Australian Democrats suffered a devastating electoral outcome in the 2004 election which significantly reduced their available budget, staff numbers and capacity to develop conventional and digital media due to the Australian system of public election financing (Alison, personal communication, 2007).

\begin{tabular}{|l|r|r|r|}
\cline { 2 - 4 } \multicolumn{1}{c|}{} & Incumbent party(ies) & Opposition party & \% difference \\
\hline Australia 2007 & 51 & 63 & 23.529 \\
\hline New Zealand 2008 & 9 & 29 & 222.222 \\
\hline Canada 2008 & 25 & 126 & 404.000 \\
\hline
\end{tabular}

Table 5: Number of online videos published by each party.

Money is not, however, the sole determinant of organisational resources. While money is clearly convertible into resources, organisational infrastructure can make the conversion of these resources more or less efficient. Two examples illustrate this. First, in the New Zealand context both the Labour Party government and the Green Party suffered from internal factors that limited their capacity to develop the type of online presence their strategies planned. For NZ Labour, its tenure in government had led its web publishing staff being divided between three different functions - party-in-government, the party's organisational website, and a campaign website (Talbot, personal communication, 2008). The NZ Greens, on the other hand, had not completed changing over to a new technology platform prior to the start of the election, limiting the functionality and flexibility of the websites they did develop (Reese, personal communication, 2009). Second, in the Canadian context the Conservative Party was afforded a considerable advantage through the possession of a large, integrated national party database allowing greater co-ordination in the use of direct communications and fundraising (Canadian Press, 2007).

\section{ii. Candidate, media choice, and funding caps}

Considering candidates' use of digital media, however, there appears to be a considerably lower impact of financial resources on the representation of candidates. This observation

33 Including website software (Content Management Systems; CMS) and third party hosting services for bandwidth-intensive content, especially the use of YouTube to host online video. 
operates at two levels. First, while campaign spending limits exist in both Canada and New Zealand, the levels of these spending caps has not yet significantly limited the ability of established party candidates to outspend (on average) smaller parties. In both nations these spending limits are still higher than the average expenditure levels of candidates of the parties of government. Thus, the conjecture that financial constraints may act as an equaliser for smaller parties is not relevant in these cases, but may become so if expenditures escalate in future.

Second, while there is a considerable difference between the levels of spending by candidates from established parties of government and minor parties in each of the elections studied, this has only a modest appreciable difference in terms of the extent to which candidates are able to establish an online presence. If we focus only on digital media, the equalisation effect for candidates can be stark. Taking the Canadian province of Ontario as an example, on average candidates of the Conservative Party spent 77.806 per cent of their legally-imposed spending limit and Liberals 70.865 per cent (the two parties of government), while those of the New Democratic Party (NPD) spent only 31.185 per cent of their limit. ${ }^{34}$ However, the NDP candidates overall online representation was very similar in relative terms. ${ }^{35}$

This equalisation is demonstrated across the three nations in Figure 1. Candidates with a tendency to have fewer resources (see graphs $c$ and $d)^{36}$ use digital media to a similar extent to those party candidates with considerably greater access to resources, most typically the parties in government (see graphs $a$ and $b$ ). However, the extent to which this represents a considerable democratic benefit (in terms of broader political dialogue and a greater plurality of voices and policy positions) is questionable. Turning to survey data ${ }^{37}$ we see that candidates from parties of government report higher levels of use of conventional media. Thus, their greater resources tend to be used to purchase more conventional advertising. ${ }^{38}$

Overall, comparative survey data tends to indicate that conventional media remains more highly valued and under-utilised ${ }^{39}$, on average, than digital media which encourages greater allocation of resources towards these types of channel. In addition, the role of central party campaign administration may reduce candidate expenditure on more expensive online "rich media", with some parties actively discouraging the use of online video by individual candidates because of the perceived loss of control over message and presentation (Davis, personal communication, 2007) or through substitution such as the provision of customisable, but centrally-developed "print ready" paper-based advertising material for distribution (Finley, personal communication, 2008).

34 The provincial average was 41.77 per cent; source: Election Canada Database, 6 May 2009.

35 That is, though the use of an aggregate measure of digital media, rather than a strict comparison of individual channels.

36 However, some established parties have noted a tendency for some resources to decline for their candidates, particularly in terms of volunteers (Finley, personal communication, 2008).

37 Australia and Canada only as New Zealand survey data is not available by party.

38 In addition, this use of push media is likely to increase the electorates awareness of these candidates' online presence (especially personal websites which are commonly listed on campaign advertising).

39 That is, candidates tend to report that conventional communications channels represent the largest gap between perceived value and actual use. It is hypothesised therefore (and the presented in Figure 1 would appear to support this hypothesis) that increased resources would be disproportionately allocated towards conventional channels. 

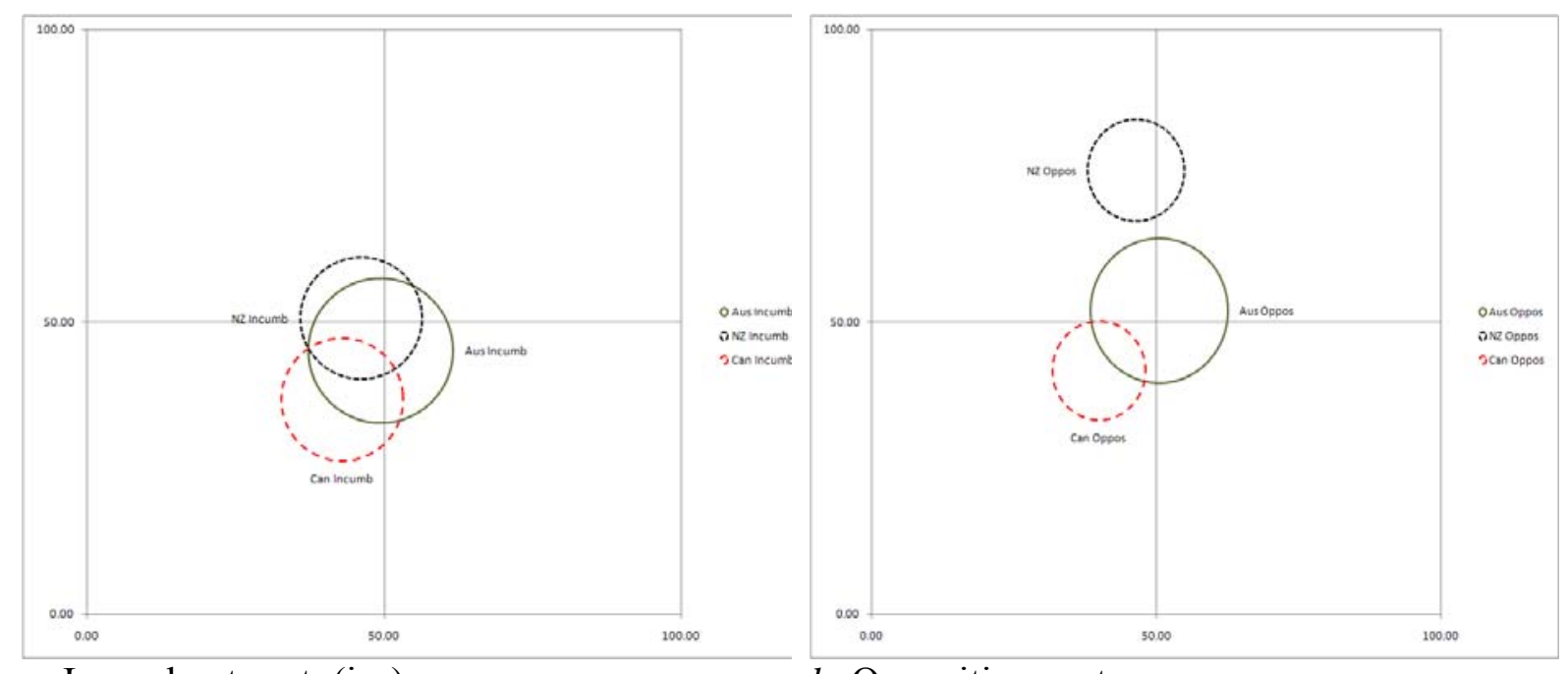

a. Incumbent party(ies)

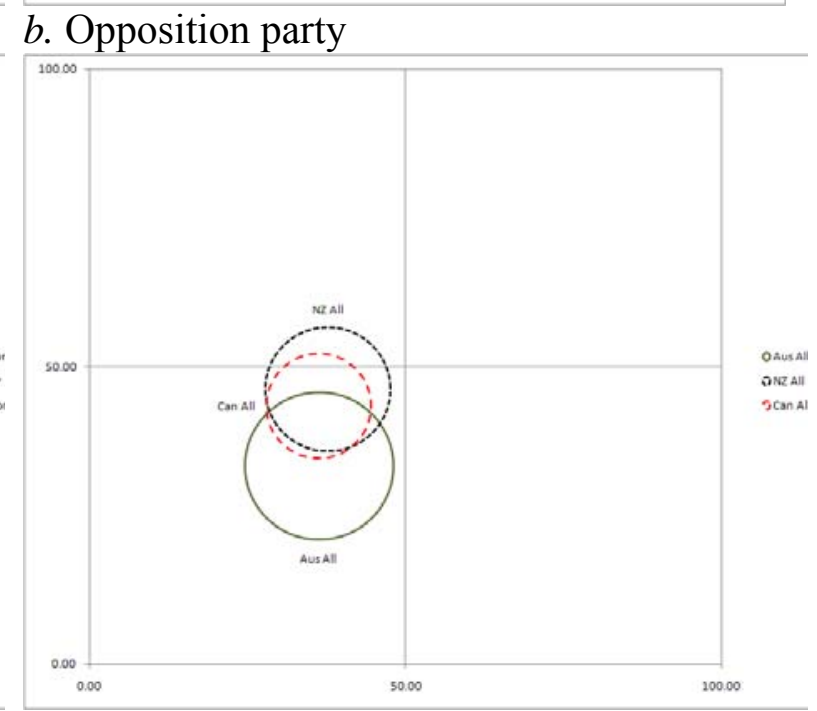

c. Minor party

d. All candidates (including independents)

Figure 1: Comparative use of digital media by candidates by party type. ${ }^{40}$

\section{iii. Organisational culture}

The New Zealand Nationals (opposition party at the 2008 election) observed that opposition parties are often encouraged by their position to be more innovative in their use of digital media (White, personal communication, 2009). This observation appears to be valid to some extent. In all three countries, the opposition parties, successful or not, tended to demonstrate considerably higher use of digital media than government parties, as illustrated in the percentage difference in video publication in Table 5.At the level of candidates, opposition candidates have tended to consistently invest more effort in attracting supporters through SNSs. This is illustrated in Figure 2 which demonstrates while minor party candidates tend, on average, to maintain more social networking profiles, opposition candidates tends to have considerably higher numbers of online supporters ("friends", social ties, etc. depending on the service). The extent to which this reflects a cultural shift of parties in opposition, or a structurating or genre effect is unclear (see below).

40 This figure is a construct created from the content analysis of candidates' use of online media. The two axes represent the number of different channels and forms of communication employed by candidates (i.e. channel 'width') and the extent to which candidates employed each channel (i.e. channel 'depth'). The size of each circle represents the boundary of one standard deviation. For a more detailed discussion of the design and limitations of this construct, see Chen (2008). 


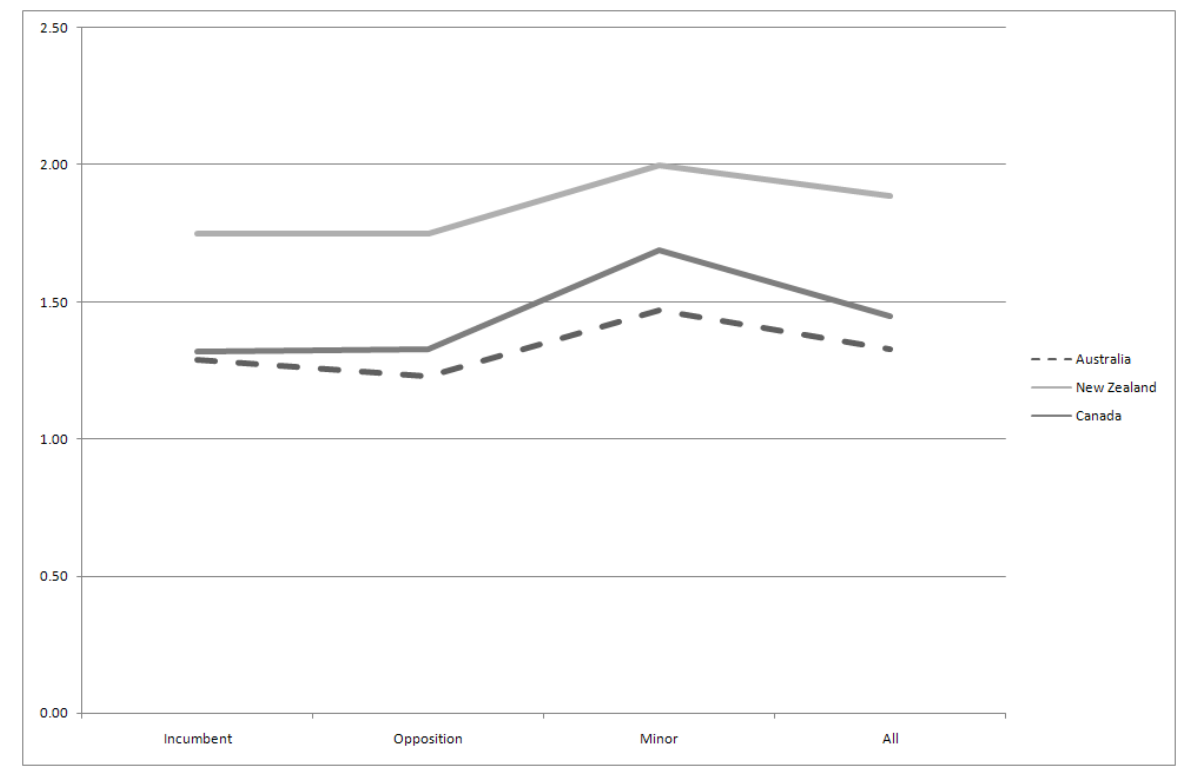

a. Average number of social networking profiles, comparative

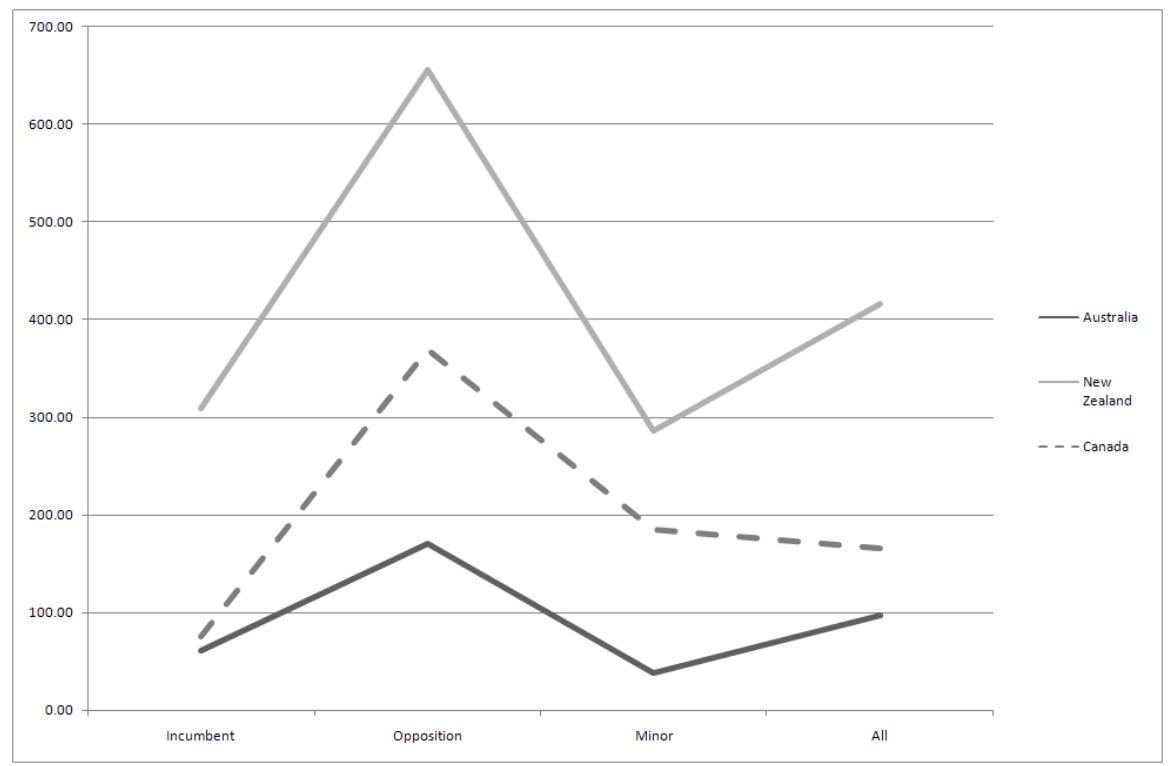

b. Population adjusted "friends", comparative

Figure 2: Use of social networking services by candidates. ${ }^{41}$

\section{Media effects factors}

\section{i. Genre effects}

The notion of 'genre effects' and its impact on the standardisation of content presentation is an interesting concept with two elements: 1) the impact of tool selection on enabling and constraining what can be said, and, 2) the impact of social and institutional position on the way in which different performativities are expressed (Butler, 1990). Evidence supports Foot,

41 Given rapid growth of SNS and the gap between the elections (eg. Australia 12 months before New Zealand), a version of figure $b$. (population adjusted) was recalibrated to include at $50 \%$ 'natural' growth rate per annum against the New Zealand numbers (50\% Australia, 4.16\% Canada). The resulting recalibrated graph was not significantly different to this figure and was therefore excluded. 
et al.'s contention that the same type of actor will the use a communication tools for a similar purpose across different contexts (Foot, et al., 2007). This was illustrated in the acquisition of SNS profiles by minor and opposition parties in Figure 2. As minor party candidates receive limited media coverage (online and off, as noted by Goot, 2008) and limited financial resources they are more likely to substitute a formal candidate website with free content hosting services. Opposition candidates engage in a disproportionately higher recruitment of supporters, regardless of the electoral outcome. In this area tool selection has a strong standardising effect on the way political information is presented, with SNS content management systems constraining the way in which these sites can be configured and used.

However, the ability of this variable to be more generally explanatory is limited. The position of political actors or the impact of standardised web publishing platforms has not yet begun to have a significant impact on the look and functionality of candidate websites (by nature the most flexible channel for online presentation). ${ }^{42}$ This is illustrated in Table 6 , an analysis of the functionality of individual candidate websites based on content analysis. What the table demonstrates is that, in individual candidate websites there exists considerable variation between the three nations, particularly around between design elements that could be associated with 'thick' and 'thin' democracy (Barber, 2002). Thus, for example, Australian candidate websites more commonly include functionality that promotes interaction between users and the candidate (surveys, feedback forms) ${ }^{43}$, while the Canadian sites tend to focus on the promotion of user action ("take action ${ }^{44}$ ). What this shows is that, at a very close level of analysis, the way in which seemingly similar looking websites are employed does display a high degree of variation between these three nations.

\begin{tabular}{|c|c|c|c|}
\hline & Australia 2007 & New Zealand 2008 & Canada 2008 \\
\hline$N$ & 45 & 76 & 124 \\
\hline $\mathrm{B} \log$ & 17.78 & 25.00 & 15.32 \\
\hline Embedded Video & 13.33 & 33.33 & 33.87 \\
\hline Feedback Form & 42.22 & 16.67 & 24.19 \\
\hline Mailing List & 22.22 & 0.00 & 25.81 \\
\hline Members Site & 2.22 & 16.67 & 3.23 \\
\hline Personalised URL & 84.44 & 83.33 & 92.74 \\
\hline Podcast & \multirow{2}{*}{$\mathrm{n} / \mathrm{a}^{45}$} & 16.67 & 8.87 \\
\hline Push to Talk & & 0.00 & 0.81 \\
\hline RSS Feed & 13.33 & 50.00 & 23.39 \\
\hline Search & 33.33 & 16.67 & 8.06 \\
\hline Sitemap & 4.44 & 8.33 & 4.03 \\
\hline Survey/Polling & 24.44 & 8.33 & 1.61 \\
\hline Take Action & 26.67 & 41.67 & 89.52 \\
\hline
\end{tabular}

Table 6: Comparative website functionality, all candidates.

42 This may be expected from the growth of freely available, high quality open source content management systems, which are increasingly dominated by a small number of market leaders such as WordPress and Joomla! (Shreves, 2008). This tendency may be delayed by the existence of legacy websites by incumbents.

43 Which is interesting, given the comparatively low level of use of e-engagement tools by Australians (Gibson, Lusoli \& Ward, 2008).

44 This includes volunteer recruitment, membership solicitation (party) and fundraising (direct or a party website gateway).

45 Not included in the 2007 version of the coding frame (Australia). 
Overall, party centralisation may end up making this debate a moot point. While not common in the three elections studied to date (only employed by the Canadian Conservative Party), candidate website templates provided and hosted by their party will standardise candidate sites (Finley, personal communication, 2008). Thus, regardless of the existence of internal competitive factors that encourage innovation by candidates within notionally centralising party systems (as discussed above), it would appear that there is a tendency for structural and organisational tendencies towards homogenisation to both support and be supported by genre effects.

\section{ii Transfer effects}

While the extent to which the technological drivers of genre effects encourage isomorphism is subject to debate, political practice in the three nations appears to have been influenced, to a more or less degree, by interjurisdictional learning. For example, ideological connection was evident in the direct use of technology providers engaged by the Canadian Liberal Party in the Obama campaign (Valpy, 2009). ${ }^{46}$ This type of transfer has been identified with more traditional campaign tools, including the tendency towards learning from parties deemed to share an ideological position (Frankel, 1997). This view was supported by some of the advocates of learning from the Obama campaign who argued that parties of the left had a more natural relationship to participative media (Reese, personal communication, 2009). The extent to which this holds to be true, however, is yet to be determined with the parties across the spectrum displaying consistently low levels of tolerance of citizen-generated media (Macnamara, 2008), ${ }^{47}$ and the use of web 2.0 type tools do not appear to be strongly determined by party position on the ideological spectrum as much as their position as incumbent or opposition. In addition, the ideological alignment is not perfect. The conservative National Party of Australia also identified the Democratic Presidential campaign as providing ideas and inspiration in their use of digital media (Henderson, personal communication, 2007).

\section{iii. Media ecosystem effects: resources and the 'ec(h)ochamber'}

While there is a tendency to focus on digital media as a channel aimed at communicating between parties/candidates and potential supporters (voters, donors, volunteers), it is also important to position this media within the content of the wider 'media ecosystem'. The media ecosystem is an interconnected set of actors, institutions and channels that permit information to move along and across media. The impact of this more complex and intense network of technologies and systems has been the increased velocity of communications commonly cited as reducing the news cycle to hours from days (Williams \& Carpini, 2004) and the need for effective communicators to understand a wider range of media formats and production requirements.

One result of these developments has been for parties to employ digital media as a means of making material available for the needs of commercial journalists (Finley, personal communication, 2008; Poorooshasb, personal communication 2008). The use of online media to distribute content, and push media particularly e-mail and mobile cellular telephones to ensure responses are delivered to journalists on breaking issues during the campaign shows

46 In the United Kingdom, Blue State Digital (a major ICT consultancy for the Obama campaign) has recently begun working with the British Labour Party.

47 A good example of this would be the NZ Green's "vote for me" campaign. This website allowed users to upload their photo and generate an electronic postcard with the parties "vote for me(us)" message superimposed over it. The strictly controlled nature of this promotional tool was preferred as a means to prevent the misuse of this type of service by malicious users and the resource constraints of the Party in monitoring what was published by users (Reese, 2009). 
how party campaign professionals recognise the constraints of journalists who are themselves caught in the new hyper-active news cycle.

What is clear, however, is that the capacity of even the largest parties to engage with emerging journalism is limited by available resources. Thus while exemplar campaigns, such as the Obama campaign's use of blog outreach to shape citizen journalism coverage of the campaign (Lutz, 2009) provided an emerging model for emulation, the extent to which parties in this study have engaged with bloggers and other citizen journalists remains tentative with only a few formalising systems to engage with bloggers during the campaign such as the Liberal Party and NDP in Canada (Miron, personal communication, 2008; Poorooshasb, personal communication 2008). Others such as the Australian Greens (Davis, personal communication, 2007) and the Australian Labor Party (Banks, personal communication, 2007) focused on the development of material that could be recycled into 'friendly' blogs or to support party themes - a more indirect, but significantly less resourceintensive approach).

The capacity of party campaigns to manage bloggers is limited, not only because of the increasing number of participants and the inability to determine the relative importance of some bloggers, but also because of their more variable operating behaviours when compared with the 'known quantity' of journalists. Given the tendency for commercial media coverage to set the agenda for blog discussion, the failure of online media to substantially alter the proportion of coverage from parties of government (incumbent and opposition) to minor parties appears to reinforce dominant institutional actors level of media exposure (Goot, 2008). While alternative media projects have been established to attempt to rebalance these inherent biases, the ability of online media to substantially alter the normalisation of a limited set of political actors is limited by the position of digital media in the wider ecosystem (Flew \& Wilson, 2008).

Overall, the extent to which the relevant media ecosystem is populated is not a function of the size of the country (nor, as we have established in Table 2, the size of the online audience). As demonstrated through identification of leaders' name mentions during the campaign in blogs, the size of the relevant blogosphere is only loosely related to population size. What this shows is that while the relevant media ecosystem in each jurisdiction has developed in similar ways (e.g. the emergence of an engaged group of citizen journalists who actively publish political commentary), the capacity for established political actors to respond in their preferred manner (attempted media control) is unequal between jurisdictions.

\section{iv. Ecosystem effects II: push becomes pull}

While the cascading effects of the media ecosystem may limit a substantial change in the level of coverage of alternative political actors, changing media literacies in voter populations do have interesting effects on the way political actors represent themselves through media. The open nature of web 2.0 tends to reiterate interjurisdictional learning and transfer effects through the creation of voter expectations about what constitutes a modern election campaign. This is evident in the New Zealand election. The opposition Party had been wary of employing Facebook as a campaigning channel for the leader John Key because of concerns about authenticity and the resource demands of responding to supporters. As the campaign developed the Party discovered that a number of supporter groups had been established independently of the Party and were attracting members, leading to the Party having to establish an official Facebook page for Key or leave his representation on this SNS in the control of third parties (White, personal communication, 2009). 


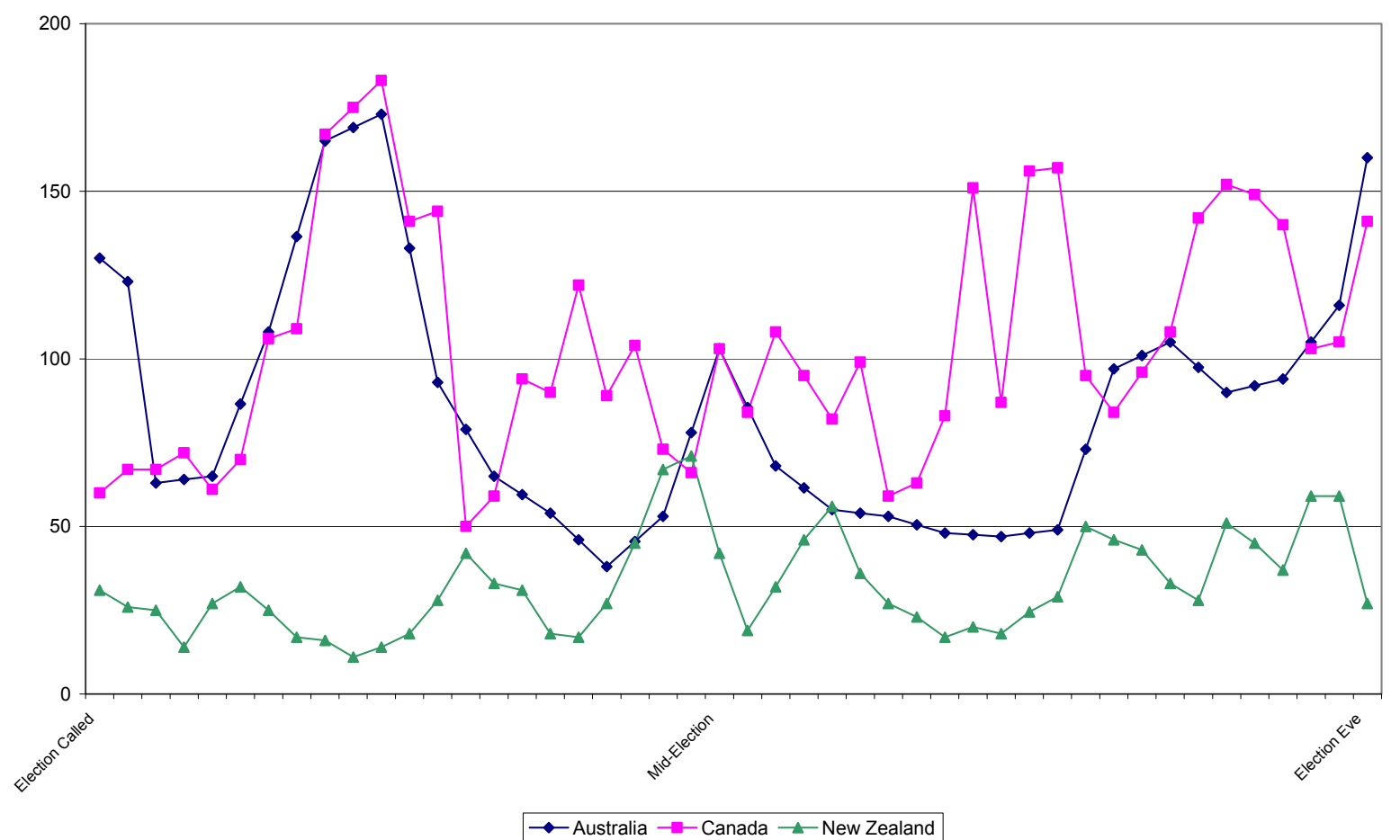

Figure 3: Total mentions per day (rescaled chronology) in blogs of government and opposition leaders. ${ }^{48}$

\section{Hybridising the debate}

At this point in the analysis it is clear that the notion of a discrete set of explanatory factors significantly fail to explain the nature of technology adoption and deployment in the three, quite similar, case examples. While a number of factors including general rates of technology adoption, "candidate centrism", and party financial resources have clear value as "best fit" variables, the interconnected nature of a variety of variables are important in understanding the idiosyncratic nature of technology adoption in different jurisdictions. As we saw in the discussion of the impacts of an increasingly dynamic and interdependent "media ecosystem", nested variables come together to create distinct patterns of behaviour.

A good example of this is interconnectivity is the story of Māori seats in New Zealand. In a political culture with a more progressive view of indigenous political representation than we see in Canada or Australia has led to a specific constitutional arrangement with distinct media effects. Under this arrangement Māori seats (seven at the 2008 election) are reserved for those Māori voters who have decided not to vote from the general roll (Māori who vote on this roll are still eligible to vote on the party list). In the $2008 \mathrm{New}$ Zealand election it is possible to identify a significant difference between general electorate and Māori electorates. As illustrated in Figure 4, Māori electorate candidates ${ }^{49}$ tend - on average - to employ a smaller number of online channels than candidates in general electorates, but invest more effort in "populating" the online channels they employed. This demonstrates an equivalent level of overall effort by candidates in Māori electorates towards online campaigning, but indicates a focus on a narrower number of channels of relevance, a rational approach given the more homogenous nature of the relevant electorate than for most candidates competing for a general electorate.

48 Source: compiled from technorati.com

49 Māori may and do also run for general electorates and under the list system, so this analysis cannot be taken as a indicative of all candidates who are Māori. 


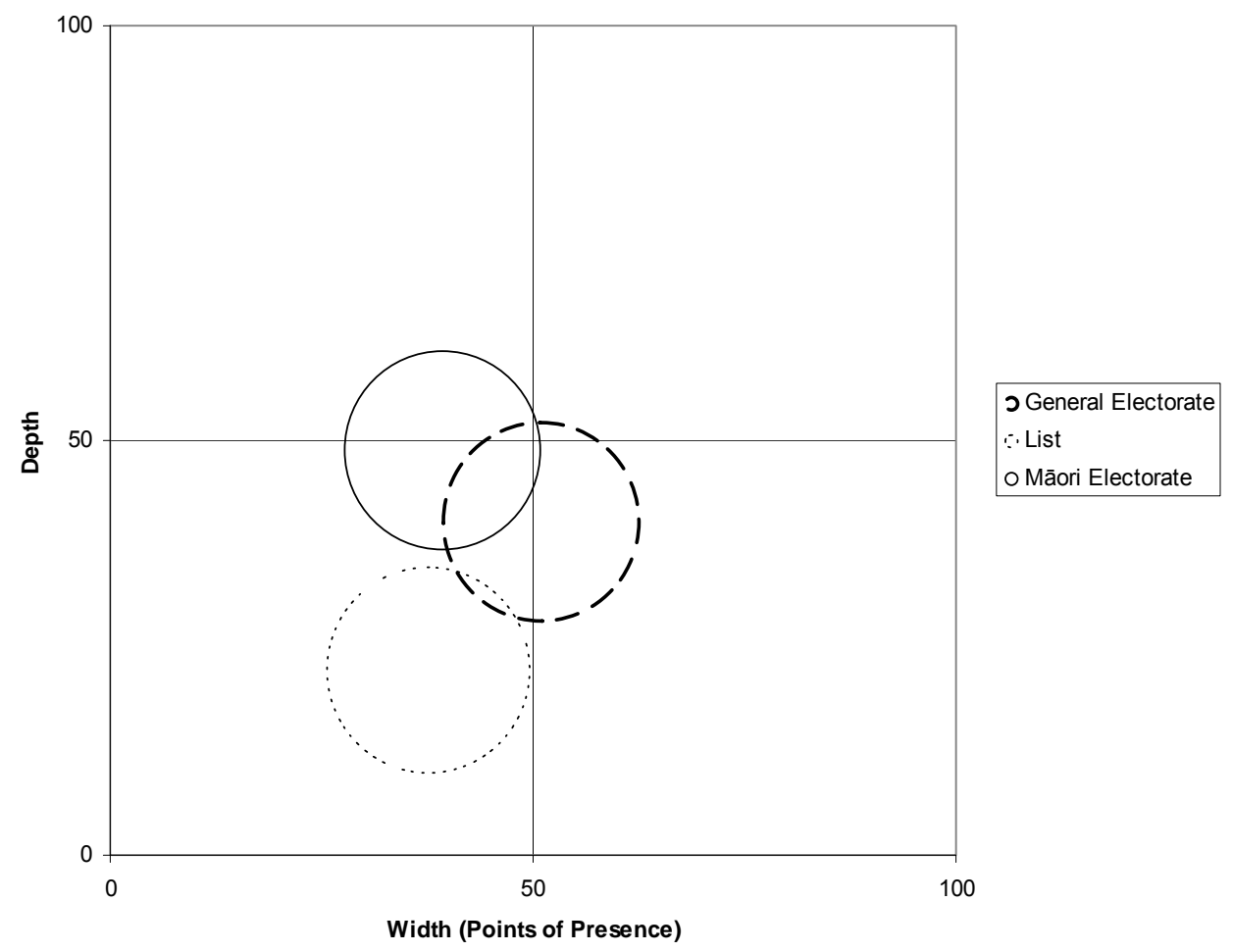

Figure 4: Comparative use of digital media by candidates in New Zealand, by type.

\section{Conclusion}

The comparative analysis of three recent national elections has provided a useful means to compare and contrast the impact of a range of variables on the political use of digital media by candidates and political parties. Clearly, the dichotomy between technological and sociostructural determinist explanations of technological adoption no longer suffices. What this study reveals is that place and context matters. The distinctive characteristic of national political systems can be seen to structure the way in which media choices are made by individuals and parties, but also has a cascading impact on a wide variety of secondary variables. Overall, we can see that there are a number of variables that have clear explanatory power in describing some aspects of political behaviour vis the adoption and use of digital media. Of particular relevance is the availability of resources and the degree to which cultural and systematic factors discourage candidate centrism and focus communications at the party level as ensuring message control either directly, through established and online/citizen journalists. Consideration of the choice of comparisons is also highlighted in this analysis. Variations in parliamentary and federal systems have differential impacts on the degree to which centralisation has occurred in each of the three countries studied. This is clearly distinct from the looser, more pluralistic presidential system of the United States which facilitates greater allowances for candidate control over digital media.

Comparisons with the United States appear to be most relevant in the way that we are able to identify the impact of genre effects and interjursdictional learning. While these variables appear important in our analysis due to a tendency towards isomorphism, they appear more selectively relevant due to specific organisational constrains on learning and emulation (capacity and infrastructure, ideology). As we examine the specific pattern of behaviour in greater detail, however, the viability of broad deterministic factors to explain the observed phenomena break down to some extent with a range of increasingly interrelated factors 
shaping the distinct way in which different channels are valued and adopted. As the interconnection between different media channels continues to develop as messages travel across, as well as along, different channels, this hybridisation appears set to intensify in future elections in these three countries. Thus, the study reveals that complexity is key to analysing the use and choice of digital media in political campaigns. Dynamism, innovation, and variations between and among similar types of political systems point in the direction of more comparative studies possibly undermining the dominance of American-centric explanations of digital media use.

\section{References}

Anstead, N., \& Chadwick, A. (2009). Parties, election campaigning, and the internet: Toward a comparative perspective. In A. Chadwick, \& P. Howard (Eds.), Routledge handbook of internet politics (pp. 56-71). New York: Routledge.

Axford, B., Browing G., Huggins R., Rosamond B., \& Turner J. (1997). Politics: An introduction. London: Routledge.

Australian Centre for Public Communication. (2008). E-Electioneering: Use of new media in the 2007 Australian federal election. Sydney: University of Technology Sydney. Retrieved November 16, 2009, from http://www.acpc.uts.edu.au/publications/e-electioneering-research-report-online.pdf

Barber, B. (1998). Which technology and which democracy? Media in transition, Massachusetts Institute of Technology, Cambridge, MA. Retrieved January 22, 2009, from http://web.mit.edu/mi-t/articles/index_barber.html

Barber, B.(1999). Three scenarios for the future of technology and strong democracy. Political Science Quarterly, Vol. 113, No. 4 (Winter), 573-589.

Barber, B. (2002). The ambiguous effects of digital technology on democracy in a globalizing world. Beitrag zum Kongress "Gut zu Wissen”, Heinrich-Böll-Stiftung, May.

Barney, D. (2000). Prometheus wired. Vancouver, Canada: UBC Press.

Boyd, D., \& Ellison N. (2007). Social network sites: definition, history, and scholarship. Journal of Computer-Mediated Communication, Vol. 13 No. 1.

Bruns, A. (2008). Blogs, Wikipedia, Second Life, and beyond: From production to produsage. New York: Peter Lang Publishing.

Butler, J. (1990). Gender trouble: Feminism and the subversion of identity. New York: Routledge.

Canadian Press. (2007). Tory database draws ire of privacy experts, CTV.ca. Retrieved October, 18, 2009, from

http://www.ctv.ca/servlet/ArticleNews/story/CTVNews/20071018/tory_privacy_071018/20071018 ?hub=QPeriod

Chen, P. (2005). E-lection 2004? New media and the campaign. In M. Simms \& J. Warhurst (Eds.), Mortgage nation: The 2004 Australian federal election. Perth: API-Bentley.

Chen, P. (2008). Candidates' new media use in the 2007 Australian national election. In F. Papandrea \& M. Armstrong (Eds.), Record of the communications policy and research forum 2008 (pp. 62 78). Sydney: Network Insight.

Chen, P. (2009). Online media. In C. Rudd, J. Haywood \& G. Craig (Eds.), Politics, media \& the New Zealand election 2008. Auckland: Pearson.

Chen, P., \& Walsh L. (2009). E-lection 2007? Political competition online', Australian Cultural History, July.

Davis, R., Owen, D., Taras, D., \& Ward, S. (2008). Conclusion. In S. Ward, D. Owen, R. Davis \& D. Taras (Eds.), Making a difference: A comparative view of the role of the internet in election politics (pp. 235 -257)/ Lanham, MA: Lexington Books.

Deuze, M. (2005). Towards professional participatory storytelling in journalism and advertising. First Monday, Vol. 10 No. 7. Retrieved May 16, 2008 from http://www.firstmonday.dk/issues/issue10_7/deuze/index.html

http://firstmonday.org/htbin/cgiwrap/bin/ojs/index.php/fm/article/viewArticle/1257/1177 
Fishkin, R., \& Pollard J. (Eds.). (2007). Search engine ranking factors V2, 2 April. Retrieved16 January 16, 2009, from http://www.seomoz.org/article/search-ranking-factors

Flew, T., \& Wilson, J. (2008). Citizen journalism and political participation: The Youdecide 2007 project and the 2007 Australian Federal Election. Australian Journal of Communication, Vol.35, No. 2, 17-37.

Frankel, B. (1997). Beyond labourism and socialism: how the Australian Labor Party developed the model of 'New Labour'. New Left Review, Issue 221 (January-February), 3 - 34.

Foot, K., Schneider S., Kluver R., Xeno, M., \& Jankowski N. (2007). Comparing web production practices across electoral web spheres. In R. Kluver, N. Jankowski, K. Foot, \& S.M Schneider (Eds.), The internet and national elections: A comparative study of web campaigning (pp. 243 260). London: Routledge.

Gibson, R., \& Ward S. (2002). Virtual campaigning: Australian parties and the impact of the internet. Australian Journal of Political Science, Vol. 37, No. 1 (March), 99-130.

Gibson, R., Wainer, L., \& Ward, S. (2008). The Australian public and politics on-line: Reinforcing or reinventing representation? Australian Journal of Political Science, Vol. 43 No. 1, 111-131.

Goot, M. (2008). Is the news on the internet different? Leaders, frontbenchers and other candidates in the 2007 Australian election. Australian Journal of Political Science, Vol. 43, No. 1, 99-110.

Hiler, J. (2002). Blogosphere: The emerging media ecosystem: How weblogs and journalists work together to report, filter and break the news. Retrieved March 21, 2009, from http://web.archive.org/web/20070116140132/

Hofferbet, R. (1974). The study of public policy. Indianapolis, IA: Bobbs-Merrill.

Jankowski, N., Kluver R., Foot K., \& Schneider, S. (2007). Introducing the internet and elections project. In R. Kluver, N. Jankowski, K. Foot, \& S.M Schneider (Eds.), The internet and national elections: A comparative study of web campaigning (pp. 3 -15). London: Routledge.

Johnston, R., \& Pattieb C. (2002). Campaigning and split-ticket voting in new electoral systems: The first MMP elections in New Zealand, Scotland and Wales. Electoral Studies, Vol. 21 No. 4 (December), 583-600.

Kidman, A. (2008). More mobiles than people in Australia, APC magaine, 29 April. Retrieved December 16, 2009, from http://apcmag.com/more_mobiles_than_people_in_australia_why.htm

Jenkins, H., \& Thorburn, D. (2004). Introduction: The digital revolution, the informed citizen, and the culture of democracy. In H. Jenkins \& D. Thorburn (Eds.), Democracy and new media (pp. 1-21). Cambridge, MA: MIT Press.

Lutz, M. (2009). The social pulpit: Barack Obama's social media toolkit. Retrieved December 16, 2009, from http://www.edelman.com/image/insights/content/Social Pulpit - Barack Obamas Social Media Toolkit 1.09.pdf

Kluver, R., Jankowski, N., Foot, K., \& Schneider, S. (Eds.). (2007). The internet and national elections: A comparative study of web campaigning. London: Routledge.

Macnamara, J. (2008). E-Electioneering: Use of new media in the 2007 Australian federal election. In E. Tilley (Ed.), Power and Place: ANZCA 2008: Proceedings of the Australian and New Zealand Communication Association Conference 2008, 9-11 July. Wellington, New Zealand: Massey University. Retrieved January 11, 2009 from http://www.massey.ac.nz/?aaac11238s

Malina, A. (1999). Perspectives on citizen democratisation and alienation in the virtual public sphere. In B. Hague \& B. Loader (Eds.), Digital democracy (pp. 23 -39). London: Routledge.

Margolis, M., \& Resnick D. (2000). Politics as usual: The cyberspace 'revolution'. London: Sage.

Naughton, J. (2006). Blogging and the emerging media ecosystem. Paper presented to Reuters Fellowship seminar, University of Oxford, 8 November. Retrieved April 29, 2008 from http://reutersinstitute.politics.ox.ac.uk/fileadmin/documents/discussion/blogging.pdf

Nieuwenhuysen, J., Lloyd P., \& Mead M. (2001). Introduction. In J. Nieuwenhuysen, P. Lloyd, \& M. Mead (Eds.), Reshaping Australia's economy: Growth with equity and sustainability (pp. 1-18). New York: Cambridge University Press.

O'Reilly, T. (2005). What is Web 2.0: Design patterns and business models for the next generation of software, 30 September. Retrieved December 16, 2009, from http://www.oreillynet.com/pub/a/oreilly/tim/news/2005/09/30/what-is-web-20.html

Rogers, E. (1983). Diffusion of innovations. New York: The Free Press. 
Schneider, S., Kluver R., Jankowski N., \& Foot K. (2007). Epilogue. In R. Kluver, N. Jankowski, K. Foot, \& S.M Schneider (Eds.), The Internet and national elections: A comparative study of web campaigning (pp. 261-264). London: Routledge.

Rhodes, R. (1992). Beyond Westminster and Whitehall: The sub-central governments of Britain. London: Routledge.

Small, T. (2008a). Equal access, unequal success - major and minor Canadian parties on the net. Party Politics, Vol. 14, No. 1 (January), 51 - 70.

Small, T. (2008b). Canada. In S. Ward, D. Owen, R. Davis \& D. Taras (Eds.), Making a difference: A comparative view of the role of the internet in election politics (pp. 113 -132). Lanham, MA: Lexington Books

Shreves, R. (2008). Open Source CMS Market Share, Summer. Retrieved December 16, 2009, from http://www.waterandstone.com/downloads/2008OpenSourceCMSMarketSurvey.pdf

Smith, P., \& Chen P. (2009a). A Canadian E-lection 2008? Online media and political competition. Paper presented at Canadian Political Science Association 81 ${ }^{\text {st }}$ Annual Conference, 27-29 May, Ottawa.

Smith, P., \& Chen P. (2009b). Digital media and election campaigning in Canada: National and provincial practices. Paper presented at $20^{\text {th }}$ ACSUS Biennial Conference, $18-22$ November, San Diego.

Valpy, M. (2009). Liberals want to mirror Obama campaign brain, The Globe and Mail, 17 April. Retrieved December 16, 2009, from http://www.pressdisplay.com/pressdisplay/showlink.aspx?bookmarkid=IJ2N89ER6TH2\&amp;pre view $=$ article \&amp;linkid $=\mathrm{d} 579 \mathrm{~d} 489-\mathrm{ab} 5 \mathrm{f}-40 \mathrm{c} 7-9872-$ c46bd2ada72d\&amp;pdaffid=cn2a2hDrBoXVKQGumXF\%2bLw\%3d\%3d

Strangelove, M. (2005). The empire of mind. Toronto, Canada: University of Toronto Press.

Ward, S. (2008). Introduction. In S. Ward, D. Owen, R. Davis \& D. Taras (Eds.), Making a difference: A comparative view of the role of the internet in election politics (pp. 1-14). Lanham, MA: Lexington Books.

Ward, S., \& Gibson, R. (2009). European political organisations and the internet: Mobilisation, participation, and change. In A. Chadwick \& P. Howard (Eds.), Handbook of internet politics (pp. 25 -39). New York: Routledge.

Ward, S., Gibson, R., \& Nixon, P. (2003). Parties and the internet: An overview. In R. Gibson, P. Nixon \& S. Ward (Eds.) Political parties and the internet: Net gain? (pp. 11 -38). New York: Routledge.

Williams B., \& Carpini, M. (2004). Monica and Bill all the time and everywhere: The collapse of gatekeeping and agenda setting in the new media environment. American Behavioral Scientist, Vol. 47, No. 9 (May), $1208-1230$.

Young, S. (2002). Spot on: The role of political advertising in Australia. Australian Journal of Political Science, Vol. 37, No.1 (March), 81-97.

Yudkin, M. (2003). Six steps to free publicity (Rev. Ed.). Franklin Lakes: Career Press.

* Dr Peter Chen is a lecturer in politics at the University of Sydney. 


\section{APPENDIX A.}

\section{Personal Interviews}

\section{Australia}

- Senator Lyn Alison, Australian Democrats. 28 November 2007.

- Simon Banks, Australian Labor Party. 17 February 2008.

- Peter Davis, Australian Greens. 19 December 2007.

- Brad Henderson, The Nationals. 10 December 2007.

\section{New Zealand}

- Conway Powell, New Zealand National Party. 18 December 2008.

- Gary Reese, Green Party of Aotearoa New Zealand. 14 January 2009.

- David Talbot, New Zealand Labour Party. 12 December 2008.

- Rhiannon White, New Zealand National Party. 23 January 2009.

\section{Canada}

- Doug Finley, Conservative Party of Canada. October 292008.

- Jim McDonald, Green Party of Canada. October 31, 2008.

- Adam Miron, Liberal Party of Canada. October 242008.

- Nammi Poorooshasb, New Democratic Party. October 302008. 